\title{
Takayasu's arteritis - aphasia as an initial presentation
}

\author{
Davinder Singh Rana, Anuradha Batra, Ish Anand, Samir Patel, Pooja Gupta \\ Department of Neurology, Old building block, Sir Ganga Ram Hospital, Old Rajinder Nagar, New Delhi 110060, India.
}

Correspondence to: Dr. Davinder Singh Rana, Department of Neurology, Old building block, Sir Ganga Ram Hospital, Old Rajinder Nagar, New Delhi 110060, India. E-mail: davinder1966@gmail.com

How to cite this article: Rana DS, Batra A, Anand I, Patel S, Gupta P. Takayasu's arteritis - aphasia as an initial presentation. Neuroimmunol Neuroinflammation 2016;3:192-5.

\section{Article history: \\ Key words: \\ Takayasu \\ arteritis \\ stroke \\ aphasia}

Received: 18-11-2015

Accepted: 13-07-2016

Published: $31-08-2016$

\section{ABSTRACT}

\begin{abstract}
Takayasu arteritis (TA) is an uncommon disease of young women, characterized by granulomatous vasculitis of medium and large arteries. Neurological involvement is reported in only a minority of patients and occurrence of neurological syndromes as the first manifestation of disease has been rarely reported. We present clinical, laboratory and imaging findings of a 40 years old lady with TA, who initially presented with clinical manifestations of stroke in form of aphasia. The rarity of the disease and especially such a presentation can cause considerable delay in the diagnosis and treatment.
\end{abstract}

\section{INTRODUCTION}

Atherosclerotic and embolic disease is common causes of ischemic stroke in both young and old patients. In the young however, a wider array of systemic and vascular diseases must be given consideration. Systemic inflammatory or autoimmune diseases, hypercoagulable states and vascular diseases such as dissection are responsible for about $20 \%$ of cases, while no certain cause is found in about one-third of young stroke victims. ${ }^{[1]}$

Takayasu arteritis (TA) is a chronic inflammatory disease of unknown etiology, characterized by granulomatous vasculitis of large and medium sized arteries, especially aorta and its branches. ${ }^{[2]}$ During the course of the disease, neurological involvement (such as transient ischemic attack, stroke, and cranial nerve palsies) is seen in $10-20 \%$ of cases. ${ }^{[3-5]}$ However, occurrence of neurological syndromes as the first manifestation of the disease has been rarely reported. ${ }^{[6-9]}$

\section{CASE REPORT}

A 40-year-old Indian female with no significant past medical history presented with sudden onset aphasia. There was no history of limb weakness or facial asymmetry. There was no known family history of cardiac, cerebrovascular or autoimmune disease. On

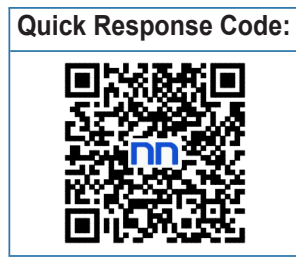



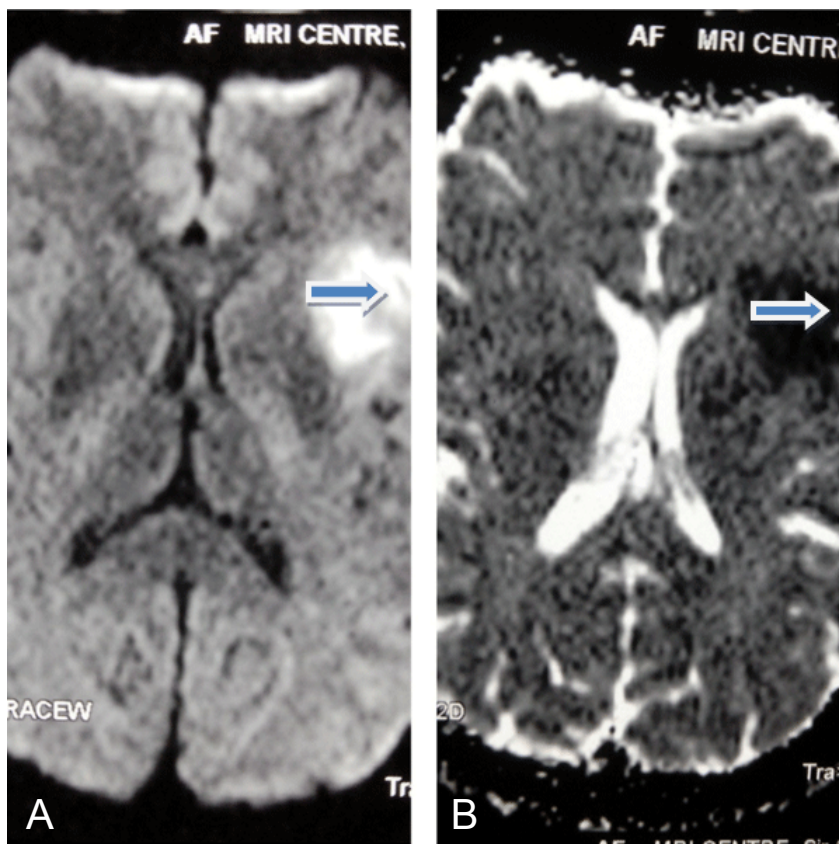

Figure 1: (A and B) Magnetic resonance imaging brain diffusion weighted imaging/apparent diffusion coefficient showing acute left perisylvian infarct

examination, the patient was moderately built and afebrile. Her left and right radial and brachial pulses were absent. Blood pressure in right upper limb was unrecordable and left upper limb was $120 / 70 \mathrm{mmHg}$. Blood pressure recorded in the lower limbs was $130 / 80 \mathrm{mmHg}$ on both the sides. There was a thrill associated with a bruit over the right carotid artery. All the lower limb pulses were felt. She had wernicke's aphasia, no facial asymmetry, limb power was normal. Cardiovascular examination was normal. There were no renal vascular bruits and optic fundi did not reveal any abnormality.

Her erythrocyte segmentation rate was $50 \mathrm{~mm} / \mathrm{h}$, total counts 5,200 cells $/ \mu \mathrm{L}, \mathrm{C}$-reactive protein was positive, and chest X-ray was normal. Electrocardiogram and holter study was within normal limit. Echo cardiography revealed normal study. Serum lipoprotein(a), homocysteine, Vit B12 level, lipid profile, Factor v leiden gene mutation, anticardiolipin antibodies, lupus anticoagulant, protein $\mathrm{C}$, protein $\mathrm{S}$, antithrombin-3 levels were found to be normal.

Magnetic resonance imaging brain revealed left perisylvian acute infarct [Figure 1]. Magnetic resonance (MR) angiography brain revealed arteritic disease involving the left internal carotid and vertebral artery [Figure 2]. MR angiography thorax and abdomen with contrast revealed diffuse concentric mural wall thickening involving ascending arch and the descending aorta causing luminal compromise [Figure 3a]. Right brachiocephalic, left common carotid and the left subclavian artery showed diffuse

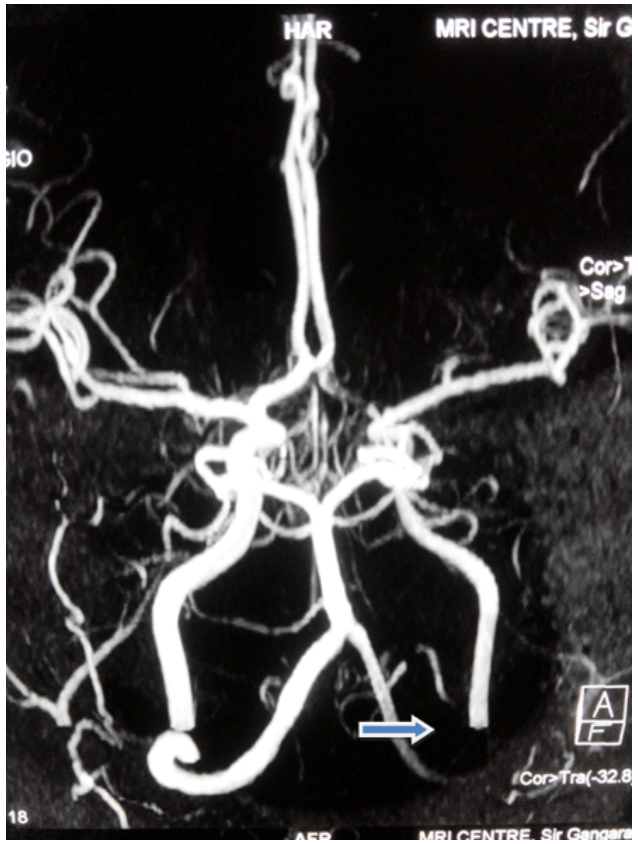

Figure 2: Magnetic resonance angiography brain showing arteritic disease involving the left internal carotid and vertebral artery

wall thickening with significant luminal compromise in right brachiocephalic artery. MR angiography neck vessels revealed significant Aorto-arteritic changes affecting all the major vessels [Figure 3b]. Given the clinical examination, laboratory studies and the findings on MR angiogram, diagnosis of Takayasu's arteritis was made. She was started on steroids and methotrexate was added subsequently. She is doing well and is also in follow up with rheumatologist. The patient is consented and agrees with this publication.

\section{DISCUSSION}

Takayasu's arteritis, also known as pulseless disease, is a chronic inflammatory disease of unknown etiology that affects the aorta and its main branches and is characterised by chronic vessel inflammation leading to wall thickening, fibrosis, stenosis, and thrombosis. It is a rare disease and was first reported in 1905 by Mikito Takayasu, ${ }^{[10]}$ an ophthalmologist, in a case with peculiar changes in the central retinal vessels. This disorder is most common in Japan and to date more than 5,000 patients have been registered by the Japanese government. ${ }^{[11]}$ Women are affected in $80 \%$ to $90 \%$ of cases, with an age of onset that is usually between 10 and 40 years. ${ }^{[12]}$ It has a worldwide distribution, with the greatest prevalence in Asians. ${ }^{[13]}$ Panja's series of 650 cases of TA, the largest series in India reported an incidence of stroke of $22 \% .{ }^{[14]}$

The etiology of Takayasu's arteritis is unknown, but evidence suggests an autoimmune process, given 


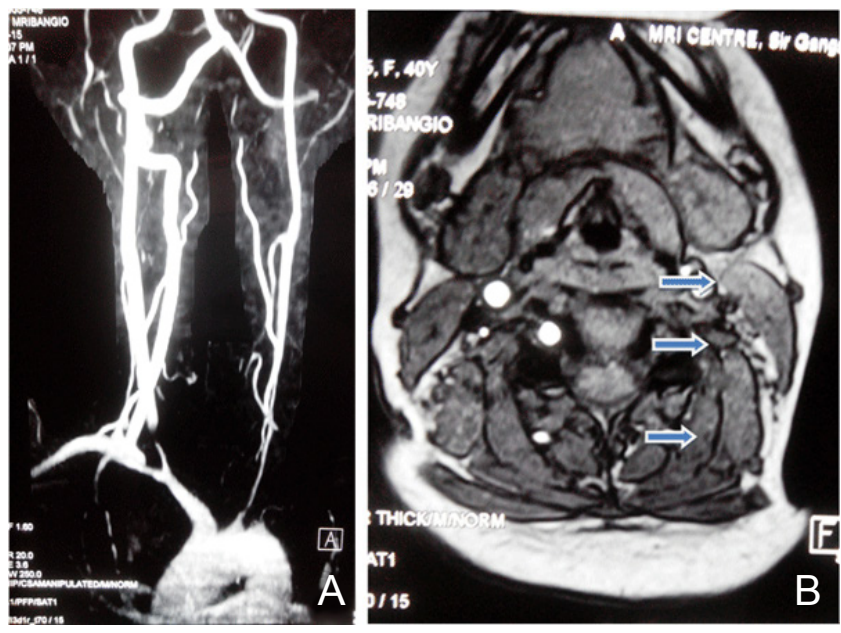

Figure 3: Magnetic resonance angiography. (A) Image of neck and thorax showing significant aorto-arteritic changes affecting all the major vessels; (B) image of neck vessels axial section showing significant aorto-arteritic changes affecting all the major vessels

the association with certain human leukocyte antigen (alleles and other autoimmune processes such as sarcoidosis and inflammatory bowel disease. It is also suggested that tuberculosis may have an association, given a high prevalence of active and past infection in patients with Takayasu's arteritis. ${ }^{[15]}$

The pattern of Takayasu's arteritis is typically triphasic, consisting of a systemic nonvascular phase, a vascular inflammatory phase, and a quiescent "burnt out" phase. ${ }^{[16]}$ The symptoms of Takayasu's arteritis vary depending on the site and degree of arterial lesions. Most patients initially present with non-specific symptoms, such as fever, night sweats, malaise and arthralgia. As the disease progresses, symptoms of end organ disease due to the ischemia, including renovascular hypertension or coronary artery disease, may develop. As inflammation progresses, stenotic lesions develop and patient develop associated symptoms. Diminished or absent pulses, vascular bruits, hypertension, retinopathy, aortic regurgitation, congestive cardiac failure, neurological manifestation and pulmonary artery involvement are some of common manifestations of these patients.

Neurological complication occurring in the chronic phase of the disease, range from asymptomatic disease to catastrophic neurological impairment and most commonly include headache, dizziness, visual disturbances, convulsive crisis, transient ischemic attack, stroke and posterior reversible encephalopathy syndrome. ${ }^{[17]}$

The American College of Rheumatology established classification criteria for the diagnosis of Takayasu's arteritis: age at disease onset $\leq 40$ years; claudication of the extremities; decreased pulsation of one or both brachial arteries; difference of at least $10 \mathrm{mmHg}$ in systolic blood pressure between the arms; bruit over one or both subclavian arteries or the abdominal aorta; arteriographic narrowing or occlusion of the entire aorta, its primary branches, or large arteries in the proximal upper or lower extremities, not due to arteriosclerosis, fibromuscular dysplasia, or other causes.

The presence of three out of six criteria is required for diagnosis and demonstrates a sensitivity of $90.5 \%$ and a specificity of $97.8 \%{ }^{[16]}$

Ultrasound, computer tomography and magnetic resonance angiography (MRA) have shown promise in the diagnosis of TA. MRA provide high resolution detail of vessel wall thickness and lumen calcification; also allow the vessel wall thickness and lumen configuration.

Steroids are the mainstay of treatment for Takayasu's arteritis. Steroid unresponsive patients can be treated with cytotoxic drugs including cyclophosphamide, azathioprine, and methotrexate. Treatment should aim to control disease activity, preserve vascular competence with minimal long term side effects. Surgical treatment is offered to those with severe stenosis of renal artery, extremity claudication, stenosis of three or more cerebral vessels, or evidence of coronary artery involvement.

Our patient had no past history of systemic manifestations like fever, joint pains, and weight loss. Neurological deficit heralded the onset of disease. She had five out of six of the criteria set forth by the American College of Rheumatology and was thus diagnosed with Takayasu's arteritis.

In conclusion, when confronted with patients with neurological problems, we should be aware of rare but possible causes, which may be treatable or at least positively modifiable with correct and timely diagnosis. Although neurological manifestations are common in patients with Takayasu's arteritis in the chronic phase, acute stroke as an initial presentation has rarely been reported. Our patient shows that Takayasu's arteritis should be considered in the differential diagnosis of young stroke. This case again emphasises the importance of looking for peripheral pulses and recording blood pressure in all four limbs at least in young stroke patients.

\section{Financial support and sponsorship} Nil.

\section{Conflicts of interest}

There are no conflicts of interest. 


\section{Patient consent Obtained.}

\section{Ethics approval}

The patient was treated within the standards of our institute and the report was approved.

\section{REFERENCES}

1. Hart RG, Miller VT. Cerebral infarction in young adults: a practical approach. Stroke 1983;14:110-4.

2. Vanoli M, Bacchiani G, Origg L, Scorza R. Takayasu's arteritis: a changing disease. J Nephrol 2001; 14:497-505.

3. Klos K, Flemming KD, Petty GW, Luthra HS. Takayasu's arteritis with arteriographic evidence of intracranial vessel involvement. Neurology 2003;60:1550-1.

4. Hoffmann M, Corr P, Robbs J. Cerebrovascular findings in Takayasu disease. J Neuroimaging 2000;10:84-90.

5. Hwang J, Kim SJ, Bang OY, Chung CS, Lee KH, Kim DK, Kim GM. Ischemic stroke in Takayasu's arteritis: lesion patterns and possible mechanisms. J Clin Neurol 2012;8:109-15.

6. Sikaroodi H, Motamedi M, Kahnooji H, Gholamrezanezhad A, Yousefi N. Stroke as the first manifestation of Takayasu arteritis. Acta Neurol Belg 2007;107:18-21.

7. Gao S, Wang R. Takayasu arteritis presenting with massive cerebral ischemic infarction in a 35 - year-old woman: a case report. $J$ Med Case Rep 2013;7:179.

8. Humayun MA, Masood A, Waseem T, Ahmad F, Raza T. An unusual cause of stroke in a young female. Am J Emerg Med 2014;32:685 e3-5.

9. Pereira VC, de Freitas CC, Luvizutto GJ, Sobreira ML, Peixoto DE, Magalhães Ido N, Bazan R, Braga GP. Stroke as the first clinical manifestation of Takayasu's arteritis. Case Rep Neurol 2014;6:271-4.

10. Takayasu M. A case with peculiar changes of the retinal cerebral vessels Acta Ophthal Soc Japan 1908;12:554-5. (in Japanese)

11. Numano F, Okawara M, Inomata H, Kobayashi Y. Takayasu's arteritis Lancet 2000;356:1023-5.

12. Lupi-Herrera E, Sánchez-Torres G, Marcushamer J, J, Mispireta J, Horwitz S, Vela JE. Takayasu's arteritis. Clinical study of 107 cases. Am Heart J 1977;93:94-103.

13. Ishikawa K. Natural history and classification of occlusive thromboaortopathy (Takayasu's disease). Circulation 1978;57:27-35.

14. Panja M, Kumar S. Long term follow up of Takayasu's disease. $J$ Am Coll Cardiol 1997;29:218A.

15. Liang $\mathrm{P}, \mathrm{Hoffman}$ GS. Advances in the medical and surgical treatment of Takayasu arteritis. Curr Opin Rheumatol 2005;17:16-24.

16. Arend WP, Michel BA, Bloch DA, Hunder GG,Calabrese LH, Edworthy SM,Fauci AS,Leavitt RY, Lie JT, Lightfoot RW Jr. The American College of Rheumatology 1990 criteria for the classification of Takayasu arteritis. Arthritis Rheum 1990;33:1129-34.

17. Zhou LX, Ni J, Gao S, Peng B, Cui LY. Neurological manifestations of Takayasu arteritis. Chin Med Sci J 2011;26:227-30. 